\title{
Influence of School Year on Seasonality of Norovirus Outbreaks in Developed Countries
}

\author{
Roni Y. Kraut, ${ }^{1}$ Kate G. Snedeker, ${ }^{2,3}$ Oksana Babenko, ${ }^{1}$ and Lance Honish ${ }^{4}$ \\ ${ }^{1}$ Department of Family Medicine, University of Alberta, Edmonton, AB, Canada T6G 2T4 \\ ${ }^{2}$ Department of Public Health Sciences, University of Alberta, Edmonton, AB, Canada T6G 1C9 \\ ${ }^{3}$ Surveillance and Reporting, Alberta Health Services, Edmonton, AB, Canada T2W 3N2 \\ ${ }^{4}$ Environmental Public Health, Alberta Health Services, Edmonton, AB, Canada T5J 2 Y2 \\ Correspondence should be addressed to Roni Y. Kraut; rkraut@ualberta.ca
}

Received 10 August 2016; Accepted 24 November 2016; Published 12 January 2017

Academic Editor: Bruno Pozzetto

Copyright (C) 2017 Roni Y. Kraut et al. This is an open access article distributed under the Creative Commons Attribution License, which permits unrestricted use, distribution, and reproduction in any medium, provided the original work is properly cited.

Factors affecting the seasonal distribution of norovirus outbreaks are not well understood. This study examined whether grade school settings at the start of the school year may be a factor. We searched Ovid Medline from January 2002 to June 2014 for studies that provided all reported norovirus outbreaks in a developed country by month for a minimum of three years. Historical school years were obtained from verifiable sources. The start of the norovirus seasonal outbreak peak and peak outbreak month were determined for each study and compared to the start month of school. Northern hemisphere and southern hemisphere countries had a different norovirus seasonality and different school year structures (traditional compared to year round). In the two studies that provided outbreaks by age, outbreaks among children started several months before outbreaks in the adult population. The median number of months between school start and start of the seasonal outbreak peak was two months (interquartile range [IQR] $=2.0-3.0$ ), while the median number of months between school start and peak outbreak month was four months (IQR $=3.0-4.0)$. These findings suggest the possibility the school setting at the start of the school year may be a factor in the seasonality of norovirus.

\section{Introduction}

Norovirus is a significant cause of gastroenteritis in developed countries worldwide [1]. In the United States alone it is estimated to cause 19-21 million cases of gastroenteritis, 400,000 emergency visits, and 570-800 deaths each year [2].

Norovirus cases in the northern hemisphere have been found to display a seasonal pattern, peaking in the fall and winter [3,4]. A variety of factors have been studied to determine the etiology behind this seasonality, including environment (temperature, rainfall, watershed conditions, population density, and gross-domestic product) and agent (norovirus genotype); however, there is still no clear explanation [4-7].

The school setting at the start of the school year has not been well explored as a factor in the seasonality of norovirus. It may provide the right interplay of factors to potentiate outbreaks: a semiclosed environment, children in close quarters, and an influx of susceptible school children.
This same combination of factors has already been found to propagate outbreaks on cruise ships $[8,9]$.

In addition, the school setting has already been found to be important in the transmission of influenza. For the 2009 pandemic, influenza cases decreased after summer vacation and increased after the resumption of the school year [10-12]. Further, studies across a diverse group of countries, including United States, Chile, Canada, and Israel, have demonstrated school closure is an effective means of decreasing influenza outbreaks among school age children $[13,14]$ and the entire population $[10,15]$.

The objective of this study was to explore whether the school setting may be a factor in the seasonality of norovirus outbreaks. Norovirus outbreaks in the province of Alberta, Canada, and selected nations were reviewed to determine if they temporally correlated with the start of the public school year. The preliminary findings were reported as a poster presentation at the 2014 Family Medicine Forum; this study elaborates on these findings [16]. 


\section{Materials and Methods}

2.1. Outbreak Data Sets. Ovid Medline was searched for papers published between January 1, 2002, and June 21, 2014, using subject headings and text words to retrieve articles related to the following concepts: norovirus, time of year, seasons, epidemiology, and disease outbreaks. The search strategy is provided in Supplementary Appendix 1 in Supplementary Material available online at https://doi.org/10.1155/2017/ 9258140. Case reports and results related to food safety, animals, and transplantation were excluded. Results were limited to the English language.

Studies were then retained if (1) they provided monthly norovirus outbreaks for a minimum of 3 years, (2) they were in a developed country [30], (3) they included all reported norovirus outbreaks from a specific region, laboratory, or reporting body, (4) they encompassed all norovirus strains, (5) outbreaks for each month were extractable, and (6) there was no age restriction on outbreak cases.

Each unique set of outbreaks was considered an outbreak set, with multicenter studies having the potential for multiple outbreak sets. From each outbreak set the following was extracted: setting of outbreaks, institution involved in collecting and reporting the outbreak data (surveillance institution), and monthly outbreak count. The total number of outbreaks extracted was compared to the total outbreaks listed in the study and was deemed to be complete if it was within $\leq 5 \%$ of the total outbreaks in the study.

The Alberta norovirus outbreaks from 2002-2012 were obtained from the Alberta Communicable Disease Reporting System. For each outbreak, date of first symptom onset, date the outbreak investigation opened, outbreak setting, and the reporting of Regional Health Authority were obtained.

The Health Panel of the University of Alberta Health Research Ethics Board approved this study.

\subsection{Start Month of Seasonal Peak and Peak Outbreak Month.} The calculations were adapted from methods described in Mounts et al. ([3] and Anthony Mounts, personal communication, 2014).

For each outbreak set, the monthly outbreak percentages were calculated by (1) computing the mean number of outbreaks for each month (the total number of outbreaks for a month, among all years, divided by the total number of years), (2) calculating the sum of the mean monthly outbreaks, and (3) dividing the mean outbreaks of each month by the sum of mean monthly outbreaks. The median outbreak percentage was calculated from the monthly outbreak percentages.

Next, for each outbreak set, the start month of the seasonal peak was determined, being the first month of at least three consecutive months where the monthly percentage of outbreaks was above the median. The peak outbreak month was also determined, being the month with the highest percentage of norovirus outbreaks.

2.3. Start Month of School. School year information, for all the years of each outbreak set, was obtained from a variety of sources. European school year information was taken from the yearly "Organization of School Time in Europe" reports [31]. New Zealand historical school year information was found on the New Zealand Ministry of Education Website [32]. For the United States, Google Trends ${ }^{\mathrm{TM}}$ was used to verify the start month of school, with the following search terms "back to school", "school start", "school year start", and "start of school year".

Surveys were sent to the Embassy of Japan in Canada (Japan), Hong Kong Education Bureau (Hong Kong), South Australia Department of Education and Child Development (Adelaide, Australia), Victoria Department of Education and Early Childhood Development (Victoria, Australia), and 22 of the school authorities in Alberta, which represented $70 \%$ of the total Alberta student population (Supplementary Appendix 2).

The median start date of school among all years was calculated for each outbreak set, except for Hong Kong, Japan, and Alberta; in these cases the start months were obtained directly from the survey. If the median start date was in the first half of the month, that month was considered the start month. If the median start date was in the second half of the month, the following month was considered the start month.

2.4. School Year Structure. Using the historical school year information, each of the data sets was determined to have either a "traditional school year" or "year round school year." Traditional school year was defined as a school year with an extended vacation in the summer, a two-week winter vacation that included Christmas and New Year's day, and no other vacations in the school year greater than one week. Year round school year was defined as a school year divided into four terms, a two- to three-week vacation between each term, and approximately a six-week break at the end of the school year.

2.5. Statistical Analysis. For each outbreak set, the number of months between the median start month of school and the start month of the seasonal peak was calculated. With these results, the median number of months and interquartile range (IQR) among all data sets were calculated. In addition, for each outbreak set, the number of months between the start month of school and the peak outbreak month was calculated. With these results, the median number of months and interquartile range among all data sets were calculated.

Statistical methods, such as time series regression analysis and the spearman correlation coefficient, were considered for determining the significance of the relationship but not undertaken due to the minimal variation in the start month across the studies (the start month was the same in 15 of the 18 studies).

\section{Results}

3.1. Outbreak Sets. There were 479 studies from the Medline search, and 15 studies, with 17 unique outbreak sets, met the selection criteria. Including Alberta data, the total number of outbreak sets was 18 (Figure 1). Table 1 shows the characteristics of each of the selected outbreak sets, including the percent of outbreaks in each setting. 
TABLE 1: Characteristics of the 18 outbreak sets.

\begin{tabular}{|c|c|c|c|c|c|}
\hline Location & Surveillance institution & Total outbreaks & Time period & $\begin{array}{c}\text { Median\% of } \\
\text { outbreaks/year } \\
\text { (IQR) }\end{array}$ & Outbreak setting \\
\hline $\begin{array}{l}\text { Australia, Adelaide } \\
\text { [1] }\end{array}$ & $\begin{array}{l}\text { Institute of Medical and } \\
\text { Veterinary Science }\end{array}$ & 136 & Jan 2001-Mar 2007 & $7 \%(4 \%-7 \%)$ & $\begin{array}{l}\mathrm{H} \text { primarily, other } \% \\
\text { not provided }\end{array}$ \\
\hline $\begin{array}{l}\text { Australia, Victoria } \\
{[17]}\end{array}$ & $\begin{array}{l}\text { Victoria Department of } \\
\text { Human Services }\end{array}$ & 1018 & Jan 2002-Dec 2007 & $14 \%(9 \%-23 \%)$ & $\begin{array}{l}\text { H 70\%, other } \% \text { not } \\
\text { provided }\end{array}$ \\
\hline Canada, Alberta & Alberta Health & 1669 & Jan 2002-Dec 2012 & $9 \%(8 \%-9 \%)$ & $\begin{array}{c}\mathrm{H} 88 \%, \mathrm{R} 3 \%, \mathrm{C} 4 \%, \mathrm{P} \\
1 \%, \mathrm{~T} 10 \%, \mathrm{O} 4 \%\end{array}$ \\
\hline $\begin{array}{l}\text { England and Wales } \\
{[18]}\end{array}$ & $\begin{array}{c}\text { Public Laboratory Service } \\
\text { Communicable Disease } \\
\text { Surveillance Centre }\end{array}$ & 1877 & Jan 1992-Dec 2000 & $11 \%(7 \%-16 \%)$ & $\begin{array}{c}\mathrm{H} 79 \%, \mathrm{R} 6 \%, \mathrm{C} 4 \%, \mathrm{P} \\
0 \%, \mathrm{~T} 8 \%, \mathrm{O} 3 \%\end{array}$ \\
\hline Germany [19] & $\begin{array}{l}\text { Robert Koch Institute, } \\
\text { Department of Infectious } \\
\text { Disease Epidemiology }\end{array}$ & 31644 & Aug 2001-Jul 2009 & $6 \%(5 \%-18 \%)$ & $\begin{array}{c}\mathrm{H} 60 \%, \mathrm{R}<1 \%, \mathrm{C} 10 \% \text {, } \\
\text { P } 24 \%, \mathrm{~T}<1 \%, \mathrm{O} 6 \%\end{array}$ \\
\hline Hong Kong [1] & $\begin{array}{l}\text { Centre for Health } \\
\text { Protection }\end{array}$ & 367 & Jan 2001-Mar 2007 & $11 \%(9 \%-15 \%)$ & Does not indicate \\
\hline $\begin{array}{l}\text { Hungary (2005) } \\
{[20]}\end{array}$ & $\begin{array}{c}\text { State Public Health Services } \\
\text { and OEK National Centre } \\
\text { for Epidemiology }{ }^{\mathrm{a}}\end{array}$ & 273 & Jan 1998-Dec 2003 & $11 \%(3 \%-28 \%)$ & $\begin{array}{c}\text { H } 58 \% \text {, R } 3 \% \text {, C } 23 \% \text {, } \\
\text { P } 0 \%, \text { T } 0 \% \text {, O } 16 \%\end{array}$ \\
\hline Hungary (2009) [1] & $\begin{array}{l}\text { Regional Institute of State } \\
\text { Public Health Services }\end{array}$ & 689 & Jan 2001-Mar 2007 & $12 \%(10 \%-17 \%)$ & $\begin{array}{l}\text { H primarily, other } \% \\
\text { not provided }\end{array}$ \\
\hline $\begin{array}{l}\text { Japan, Osaka City } \\
(2002)[21]\end{array}$ & $\begin{array}{l}\text { Osaka City Institute of } \\
\text { Public Health and } \\
\text { Environmental Sciences }\end{array}$ & 64 & $\begin{array}{l}\text { Apr 1996-Mar } \\
2000\end{array}$ & $20 \%(15 \%-29 \%)$ & $\begin{array}{c}\mathrm{H} 0 \%, \mathrm{R} 47 \%, \mathrm{C} 0 \%, \mathrm{P} \\
0 \%, \mathrm{~T} 24 \% \text {, O } 29 \%\end{array}$ \\
\hline $\begin{array}{l}\text { Japan, Osaka City } \\
\text { (2009) [1] }\end{array}$ & $\begin{array}{l}\text { Osaka City Institute of } \\
\text { Public Health and } \\
\text { Environmental Sciences }\end{array}$ & 317 & Jan 2001-Mar 2007 & $20 \%(15 \%-29 \%)$ & Does not indicate \\
\hline Netherlands [22] & $\begin{array}{c}\text { National Institute of Public } \\
\text { Health and the } \\
\text { Environment }\end{array}$ & 695 & $\begin{array}{l}\text { Dec } 1994-\mathrm{Dec} \\
2005\end{array}$ & $6 \%(4 \%-9 \%)$ & $\begin{array}{c}\mathrm{H} 79 \%, \mathrm{R} 8 \%, \mathrm{C} 5 \%, \mathrm{P} \\
0 \%, \mathrm{~T} 2 \%, \mathrm{O} 6 \%\end{array}$ \\
\hline New Zealand [23] & $\begin{array}{c}\text { New Zealand Ministry of } \\
\text { Health }\end{array}$ & 1206 & Jan 2002-Dec 2009 & $14 \%(7 \%-16 \%)$ & $\begin{array}{c}\text { H } 64 \%, \text { R } 17 \%, \text { C } 5 \%, \\
\text { P } 5 \%, \text { T } 4 \% \text {, O 5\% }\end{array}$ \\
\hline Norway [24] & $\begin{array}{l}\text { Norwegian Institute of } \\
\text { Public Health }\end{array}$ & 204 & Jan 2001-Aug 2005 & $13 \%(12 \%-32 \%)$ & $\begin{array}{l}\text { H 84\%, other\% not } \\
\text { provided }\end{array}$ \\
\hline $\begin{array}{l}\text { Spain, Catalonia } \\
{[25]}\end{array}$ & $\begin{array}{c}\text { Public Health Agency of } \\
\text { Catalonia }\end{array}$ & 128 & Jan 2010-Dec 2012 & $27 \%(25 \%-38 \%)$ & $\begin{array}{c}\text { H } 28 \% \text {, R } 30 \% \text {, C } 9 \% \text {, } \\
\text { P 9\%, T } 14 \% \text {, O 10\% }\end{array}$ \\
\hline $\begin{array}{l}\text { Spain, Catalonia } \\
\text { and Valencia [26] }\end{array}$ & Not indicated & 169 & Jan 2001-Dec 2006 & $13 \%(12 \%-24 \%)$ & $\begin{array}{l}\text { H } 35 \%, \text { R } 16 \% \text {, C 7\%, } \\
\text { P } 10 \% \text {, T } 25 \% \text {, O 7\% }\end{array}$ \\
\hline US (2002) [27] & $\begin{array}{l}\text { Centre for Disease Control } \\
\text { and Prevention }\end{array}$ & 201 & Jul 1997-Jun 2000 & $23 \%(18 \%-30 \%)$ & $\begin{array}{c}\text { H } 25 \%, \text { R } 39 \%, \text { C } 13 \% \text {, } \\
\text { P } 0 \%, \text { T } 10 \% \text {, O 12\% }\end{array}$ \\
\hline US (2006) [28] & $\begin{array}{l}\text { Centre for Disease Control } \\
\text { and Prevention }\end{array}$ & 184 & Jul 2000-Jun 2004 & $20 \%(19 \%-22 \%)$ & $\begin{array}{c}\text { H } 31 \% \text {, R } 28 \%, \text { C } 11 \% \text {, } \\
\text { P } 2 \% \text { T } 18 \% \text {, O } 10 \%\end{array}$ \\
\hline US (2011) [29] & $\begin{array}{l}\text { State and territorial public } \\
\text { health departments }\end{array}$ & 2866 & Jan 2007-Apr 2010 & $27 \%(24 \%-28 \%)$ & $\begin{array}{l}\text { H } 65 \% \text {, other } \% \text { not } \\
\text { provided }\end{array}$ \\
\hline
\end{tabular}

C, daycare, school, and camps; $\mathrm{H}$, hospital and long term care institution; $\mathrm{O}$, other; $\mathrm{P}$, private home; $\mathrm{R}$, restaurant and catering; $\mathrm{T}$, travel hotel.

${ }^{\text {a }}$ Surveillance institution determined by author affiliation.

3.2. Start Month of Seasonal Peak and Peak Outbreak Month. In the majority of outbreak sets, the start month of seasonal peak was in October/November (fall) and the peak outbreak month was approximately 2 months later in December/January (winter). However in Victoria, Australia, and New Zealand, the start month of seasonal peak was in June/July (winter) and the peak outbreak month was approximately 4 months later, in October (spring).
In addition, the majority of outbreak sets showed similar distribution of outbreaks, with the start month of seasonal peak preceding the peak outbreak month (Figure 2). In the United States (1997-2000) and Catalonia (2010-2012), however, the peak outbreak month preceded the start month of seasonal peak, and in Catalonia and Valencia (20012006), a start month of seasonal peak was not present. Supplementary Appendix 3 provides the details. 


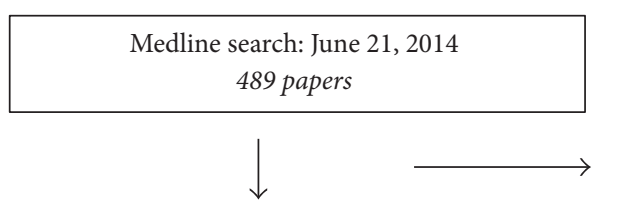

Accessible studies with outbreaks/month 104 papers

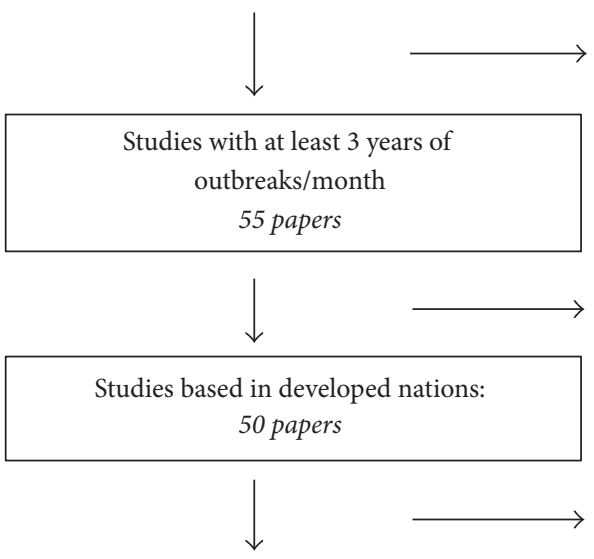

Potential studies for data extraction: 45 papers

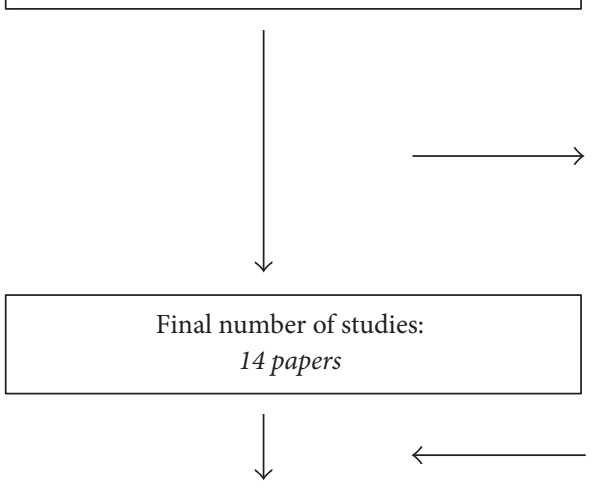

Distinct outbreak sets: 17

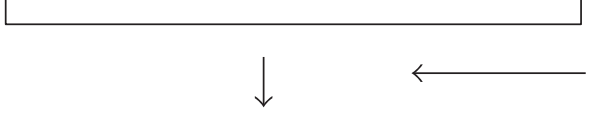

Final outbreak sets: 18
Studies without norovirus outbreaks per month: 384

Studies unable to access: 1

Studies based in developing country: 5

Papers with outbreaks from only 1 setting:

hospital (3), long term care (2)

Excluded (31):

Unable to extract outbreaks: 7

Cumulative outbreaks by month for all years: 5

Did not include all norovirus strains: 5

Duplicate data set: 5

Other: aggregated outbreaks of several countries (1), years not

labeled on graph (1), not having absolute outbreaks (1),

outbreaks based on mathematical model (2), provided subset of

outbreaks (2), only sporadic outbreaks (2)

1 multicentre paper: 3 applicable outbreak sets

Alberta, Canada, data from Alberta communicable disease reporting system

FIgURE 1: Outbreak set selection.

3.3. Start Month of School. The response rate to the Hong Kong, Japan, and Australia surveys was 100\%. In Alberta, five school districts responded, representing $23.9 \%$ of the total school population in Alberta. In addition, a quarter of European school year dates were not obtained, due to several years without published Eurydice reports. The start month of school for all regions, except Australia and New Zealand, was determined to be September (Table 2). In Australia and New Zealand the start month of school was February.

3.4. School Year Structure. All of the regions, with the exception of Australia, New Zealand, and Germany, had a school year most consistent with a traditional school year. Australia and New Zealand outbreak sets had year round 


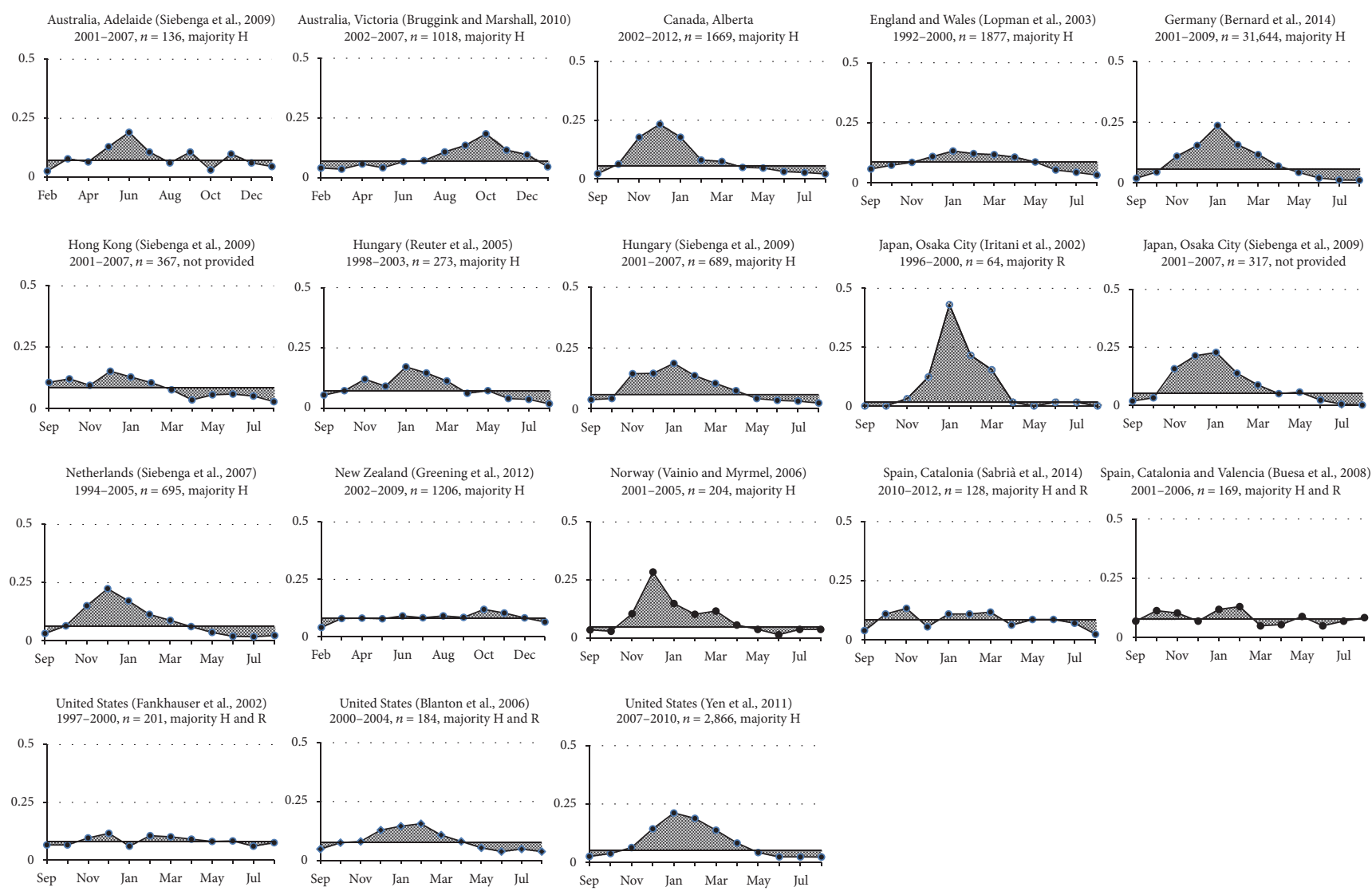

FIGURE 2: Monthly outbreak percentages of each outbreak set. Horizontal axis: month of the year, first month is school start month. Vertical axis: outbreak percentage. Solid vertical line: median outbreak percentage. H: hospital and long term care setting. R: restaurant and catered setting.

school years. Germany had characteristics of both traditional and year round school years.

3.5. Statistical Analysis. The median number of months between the start of school month and the start month of seasonal peak was two months (IQR 2.0-3.0) (Figure 3). The median number of months between the start of school month and the peak outbreak month was four months (IQR 3.0-4.0) (Figure 3).

\section{Discussion}

These findings, taken together, suggest the seasonality of norovirus induced gastroenteritis outbreaks may be related to the school setting at the start of the school year. Further, the outbreak sets used in the study provided credible outbreak data; all had three or more years of outbreak data and were collected by the regional or national surveillance institutions, and the majority did not have significantly skewed distributions.

The median time period between the start of the school year and the peak outbreak month, four months, corresponds to mathematical simulations by London and Yorke [33].

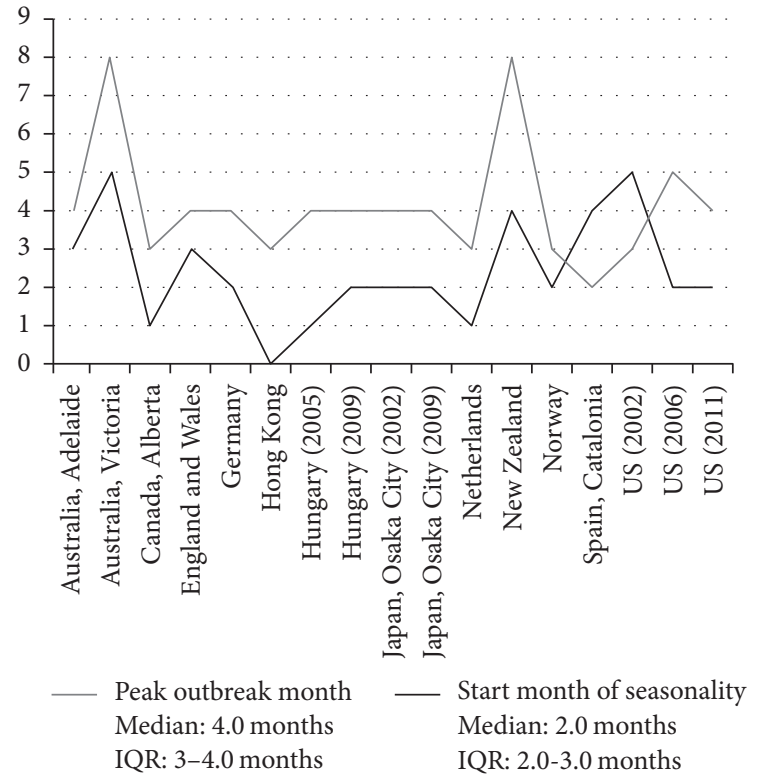

FIGURE 3: Start month of seasonal peak and peak outbreak month relative to start of school month by data set. Vertical axis: number of months after school year start month. 
TABLE 2: School year characteristics of outbreak set regions.

\begin{tabular}{|c|c|c|c|c|}
\hline \multirow[b]{2}{*}{ Location } & \multirow[b]{2}{*}{ Source } & \multirow{2}{*}{$\begin{array}{l}\text { School year type; holidays } \\
\quad>1 \text { week }\end{array}$} & \multicolumn{2}{|c|}{ School year } \\
\hline & & & $\begin{array}{l}\text { Median start date } \\
\text { (IQR) }\end{array}$ & Start month \\
\hline $\begin{array}{l}\text { Australia, South } \\
\text { Australia }\end{array}$ & $\begin{array}{c}\text { South Australia Department of Education } \\
\text { and Child } \\
\text { Development (survey) }\end{array}$ & $\mathrm{Y}$ & $\begin{array}{l}\text { Jan } 29 \\
(28-29)\end{array}$ & February \\
\hline Australia, Victoria & $\begin{array}{c}\text { Victoria Department of } \\
\text { Education and Early Childhood } \\
\text { Development (survey) }\end{array}$ & $\mathrm{Y}$ & $\begin{array}{l}\text { Jan } 29 \\
(29-30)\end{array}$ & February \\
\hline Canada, Alberta & Alberta school authorities (survey) & $\mathrm{T}: \mathrm{CV}, \mathrm{SuV}$ & NA & September \\
\hline England and Wales & Eurydice & T: CV, SV, SuV & $\begin{array}{l}\text { Sep } 4 \\
(1-8)\end{array}$ & September \\
\hline Germany & Eurydice & $\mathrm{U}: \mathrm{AV}, \mathrm{CV}, \mathrm{SV}, \mathrm{SuV}$ & $\begin{array}{l}\text { Aug } 23 \\
(16-25)\end{array}$ & September \\
\hline Hong Kong & Hong Kong Education Bureau (survey) & T: no data & NA & September \\
\hline Hungary & Eurydice & T: CV, SuV & $\begin{array}{c}\text { Sep 1 } \\
\text { (Aug 31-Sep 1) }\end{array}$ & September \\
\hline Japan $^{\mathrm{a}}$ & Embassy of Japan in Canada (survey) & T: CV, SV, SuV & NA & September \\
\hline Netherlands & Eurydice & T: CV, SuV & $\begin{array}{l}\text { Aug 23 } \\
(22-25) \mathrm{p} \\
\text { Aug } 27 \\
(26-29) \mathrm{s}\end{array}$ & September \\
\hline New Zealand & $\begin{array}{l}\text { New Zealand Ministry of Education } \\
\text { website }\end{array}$ & $\mathrm{Y}$ & $\begin{array}{c}\text { Feb } 1 \\
(\operatorname{Jan} 29-F e b 7)\end{array}$ & February \\
\hline Norway & Eurydice & T: CV, SuV & $\begin{array}{l}\text { Aug } 19 \\
(18-19)\end{array}$ & September \\
\hline Spain, Catalonia & Eurydice & T: CV, SuV & $\begin{array}{l}\text { Sep } 7 \\
(7-7)\end{array}$ & September \\
\hline $\begin{array}{l}\text { Spain, Catalonia } \\
\text { and Valencia }\end{array}$ & Eurydice & T: CV, SuV & $\begin{array}{l}\text { Sep } 11 \\
(9-15) \mathrm{p} \\
\text { Sep } 15 \\
(15-17) \mathrm{s}\end{array}$ & September \\
\hline US & Google trends & T: no data & NA & September \\
\hline
\end{tabular}

School year type: Y: year round, T: traditional, U: unclear.

Holidays: AV: autumn, CV: Christmas/New Years, SV: spring, SuV: summer.

Age level: p: primary, s: secondary.

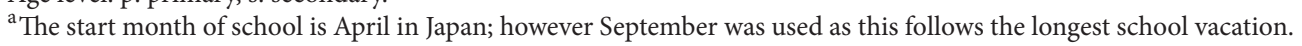

London and Yorke showed the delay of the start of mixing of new susceptibles to peak outbreaks in a population may be explained by the incubation period, the incubation period being the number of days from exposure to infectivity. Norovirus, with an incubation period of approximately two days [34], requires four months [33], whereas measles (incubation period of approximately 14 days [35]) requires approximately eight months [33].

The three outbreak sets without a clear seasonality, United States 2002 and Spain 2008 and 2014, had the majority of outbreak cases in settings other than health care institutions (Table 1). This appears consistent with previous research by Lopman et al. indicating that norovirus outbreaks in health institutions display a seasonal pattern, whereas the norovirus outbreaks in the community setting do not [18]. Alberta data showed similar results; only health institutions, schools, and child care settings displayed clear seasonality (Supplementary Appendix 4).
The German and Alberta outbreak sets were the only ones that provided information on seasonality of outbreaks by age group; the other studies primarily focused on genotype. Outbreaks in Germany started six weeks earlier in child care institutions and schools than in the general population [19]. Alberta data had similar findings; the start month of the seasonal peak of Alberta school outbreaks was two months earlier than the start month of outbreaks in health care settings (Supplementary Appendix 4).

The seasonality of norovirus cases in southern hemisphere countries is unclear. A recent systematic review and meta-analysis indicated there was not a consistent seasonality to outbreaks in the southern hemisphere, based on nine studies (four outbreaks and five sporadic cases) [4]. The authors suggested it may be due to a different epidemiologic pattern or lack of robust data, as only three studies had more than two years of data, and only one of these had populationwide data. 
Traditional school year regions

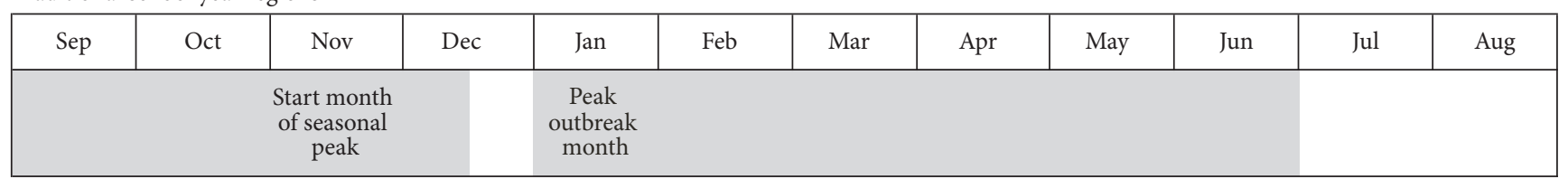

Year round school year regions

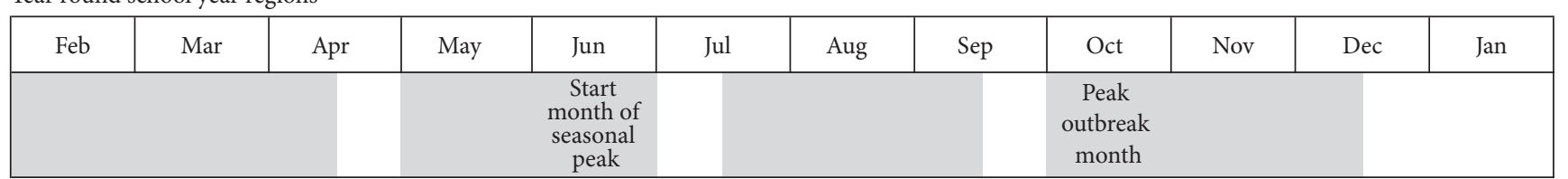

FIGURE 4: Comparison of type of school year with outbreak timing. School time is shaded and vacation time is shown in white. These dates are calculated based on median dates of the applicable data sets. If the majority of the median holiday dates was past mid-month, the holiday was considered to be the last 2 weeks of the month, if the majority of the median holiday dates was prior to mid-month, the holiday was considered to be in the first 2 weeks of the month.

Our study included three southern hemisphere outbreak sets (Victoria Australia, New Zealand, and Adelaide Australia), with each having more than 3 years of populationwide monthly outbreaks. The first two clearly had a start month of seasonal peak in June/July and peak outbreak month in October, while Adelaide was different. However Adelaide had a total of 136 outbreaks over a seven-year time period, with 94 of these outbreaks in 2006. If the 2006 outbreak data is removed, the start month of seasonal peak is August and peak outbreak month is November (Supplementary Appendix 3).

The differing seasonality we found between the northern and southern hemisphere countries supports the previous 2013 systematic review, which found little association between weather conditions and seasonality of norovirus [4]. Alternatively, the school year may be contributing to these differences. Australia and New Zealand have year round schooling with a two-week holiday, two and a half months after the start of school. This may decrease the close contact and transmission of norovirus among school children. The northern hemisphere countries have a traditional school year, with a two-week holiday, three and a half months after the start of school (Figure 4). Further studies are required to both fully determine the seasonality of norovirus in the southern hemispheres and investigate the possible factors involved in the seasonality, including the school year.

This study is limited to analysis on a monthly basis instead of a weekly basis. Analysis on a weekly basis would better be able to determine the relationships between outbreaks and school year and allow for further statistical analysis. In addition, the data in this study was collected by more than 16 different surveillance organizations, each having their own individual surveillance methods. However, all the surveillance organizations are regional or national bodies, seasonality was generally consistent across the studies, and key studies in the past have examined outbreaks of different surveillance institutions together $[1,4]$.

The school setting at the start of the school year has the potential to be a factor in norovirus seasonality. The large German outbreak set with 31,644 outbreaks would seem ideal for future research, as there is substantial variation in school years across German states. In addition, further research could consider incidence, genotypes, and timing of norovirus cases in schools compared to health care institutions and whether improved norovirus surveillance and preventative measures in schools, including improved hand hygiene, lower the incidence of norovirus in the general population.

\section{Competing Interests}

The authors declare that there is no conflict of interests regarding the publication of this paper.

\section{Acknowledgments}

The authors would like to thank Larry Svenson, Alberta Health, and Dr. Gerry Predy, Alberta Health Services, for their support and resources, and Dale Storie, medical librarian, for his assistance with the literature search.

\section{References}

[1] J. J. Siebenga, H. Vennema, D.-P. Zheng et al., "Norovirus illness is a global problem: emergence and spread of norovirus GII.4 variants, 2001-2007," Journal of Infectious Diseases, vol. 200, no. 5, pp. 802-812, 2009.

[2] Centers for Disease Control and Prevention, "Norovirus, US Trends and Outbreaks," http://www.cdc.gov/norovirus/trendsoutbreaks.html\#outbreaks.

[3] A. W. Mounts, T. Ando, M. Koopmans, J. S. Bresee, J. Noel, and R. I. Glass, "Cold weather seasonality of gastroenteritis associated with Norwalk-like viruses," Journal of Infectious Diseases, vol. 181, no. 2, pp. S284-S287, 2000.

[4] S. M. Ahmed, B. A. Lopman, and K. Levy, "A systematic review and meta-analysis of the global seasonality of norovirus," PLoS ONE, vol. 8, no. 10, Article ID e75922, 2013.

[5] J. A. Marshall and L. D. Bruggink, "The dynamics of norovirus outbreak epidemics: recent insights," International Journal of Environmental Research and Public Health, vol. 8, no. 4, pp. 11411149, 2011. 
[6] A. L. Greer, S. J. Drews, and D. N. Fisman, "Why 'Winter' vomiting disease? Seasonality, hydrology, and norovirus epidemiology in Toronto, Canada," EcoHealth, vol. 6, no. 2, pp. 192199, 2009.

[7] M. E. Hasing, B. E. Lee, J. K. Preiksaitis et al., "Emergence of a new norovirus GII.4 variant and changes in the historical biennial pattern of norovirus outbreak activity in Alberta, Canada, from 2008 to 2013," Journal of Clinical Microbiology, vol. 51, no. 7, pp. 2204-2211, 2013.

[8] Centers for Disease Control and Prevention, "Vessel sanitation program: facts about noroviruses on cruise ships," https://www.cdc.gov/nceh/vsp/pub/norovirus/norovirus.htm.

[9] L. Verhoef, E. Depoortere, I. Boxman et al., "Emergence of new norovirus variants on spring cruise ships and prediction of winter epidemics," Emerging Infectious Diseases, vol. 14, no. 2, pp. 238-243, 2008.

[10] D. J. D. Earn, D. He, M. B. Loeb, K. Fonseca, B. E. Lee, and J. Dushoff, "Effects of school closure on incidence of pandemic influenza in Alberta, Canada," Annals of Internal Medicine, vol. 156, no. 3, pp. 173-181, 2012.

[11] D. L. Chao, M. E. Halloran, and I. M. Longini Jr., "School opening dates predict pandemic influenza $\mathrm{A}(\mathrm{H} 1 \mathrm{~N} 1)$ outbreaks in the United States," The Journal of Infectious Diseases, vol. 202, no. 6, pp. 877-880, 2010.

[12] J. T. Wu, B. J. Cowling, E. H. Y. Lau et al., "School closure and mitigation of pandemic (H1N1) 2009, Hong Kong," Emerging Infectious Diseases, vol. 16, no. 3, pp. 538-541, 2010.

[13] G. Chowell, S. Towers, C. Viboud, R. Fuentes, and V. Sotomayor, "Illness and winter school breaks, Chili, 2004-2010," Emerging Infectious Diseases Journal, vol. 20, pp. 1203-1207, 2014.

[14] C. C. Wheeler, L. M. Erhart, and M. L. Jehn, "Effect of school closure on the incidence of influenza among school-age children in Arizona," Public Health Reports, vol. 125, no. 6, pp. 851-859, 2010.

[15] A. Heymann, G. Chodick, B. Reichman, E. Kokia, and J. Laufer, "Influence of school closure on the incidence of viral respiratory diseases among children and on health care utilization," Pediatric Infectious Disease Journal, vol. 23, no. 7, pp. 675-677, 2004.

[16] R. Y. Kraut, K. Snedeker, and L. Honish, "Influence of school year on seasonality of norovirus outbreaks in developed countries," Poster presented at Family Medicine Forum Presentation, Toronto, Canada, November 2014, http://fmf.cfpc.ca/wpcontent/uploads/2014/11/RESEARCH-DAY.pdf.

[17] L. D. Bruggink and J. A. Marshall, "Molecular changes associated with altered patterns of Norovirus outbreak epidemics in Victoria, Australia, in 2006 to 2007,' Journal of Clinical Microbiology, vol. 48, no. 3, pp. 857-861, 2010.

[18] B. A. Lopman, G. K. Adak, M. H. Reacher, and D. W. G. Brown, "Two epidemiologic patterns of Norovirus outbreaks: surveillance in England and Wales, 1992-2000," Emerging Infectious Diseases, vol. 9, no. 1, pp. 71-77, 2003.

[19] H. Bernard, M. Höhne, S. Niendorf, D. Altmann, and K. Stark, "Epidemiology of norovirus gastroenteritis in Germany 20012009: eight seasons of routine surveillance," Epidemiology and Infection, vol. 142, no. 1, pp. 63-74, 2014.

[20] G. Reuter, K. Krisztalovics, H. Vennema, M. Koopmans, and G. Szucs, "Evidence of the etiological predominance of norovirus in gastroenteritis outbreaks-emerging new-variant and recombinant noroviruses in Hungary," Journal of Medical Virology, vol. 76, no. 4, pp. 598-607, 2005.

[21] N. Iritani, Y. Seto, H. Kubo, K. Haruki, M. Ayata, and H. Ogura, "Prevalence of 'Norwalk-like virus' infections in outbreaks of acute nonbacterial gastroenteritis observed during the 19992000 season in Osaka City, Japan," Journal of Medical Virology, vol. 66, no. 1, pp. 131-138, 2002.

[22] J. J. Siebenga, H. Vennema, E. Duizer, and M. P. G. Koopmans, "Gastroenteritis caused by norovirus GGII.4, the Netherlands, 1994-2005,” Emerging Infectious Diseases, vol. 13, no. 1, pp. 144146, 2007.

[23] G. E. Greening, J. Hewitt, M. Rivera-Aban, and D. Croucher, "Molecular epidemiology of norovirus gastroenteritis outbreaks in New Zealand from 2002-2009," Journal of Medical Virology, vol. 84, no. 9, pp. 1449-1458, 2012.

[24] K. Vainio and M. Myrmel, "Molecular epidemiology of norovirus outbreaks in Norway during 2000 to 2005 and comparison of four norovirus real-time reverse transcriptase PCR assays," Journal of Clinical Microbiology, vol. 44, no. 10, pp. 3695-3702, 2006.

[25] A. Sabrià, R. M. Pintó, A. Bosch et al., "Molecular and clinical epidemiology of norovirus outbreaks in Spain during the emergence of GII.4 2012 variant," Journal of Clinical Virology, vol. 60, no. 2, pp. 96-104, 2014.

[26] J. Buesa, R. Montava, R. Abu-Mallouh et al., "Sequential evolution of genotype GII.4 norovirus variants causing gastroenteritis outbreaks from 2001 to 2006 in Eastern Spain," Journal of Medical Virology, vol. 80, no. 7, pp. 1288-1295, 2008.

[27] R. L. Fankhauser, S. S. Monroe, J. S. Noel et al., "Epidemiologic and molecular trends of 'Norwalk-like viruses' associated with outbreaks of gastroenteritis in the United States," Journal of Infectious Diseases, vol. 186, no. 1, pp. 1-7, 2002.

[28] L. H. Blanton, S. M. Adams, R. S. Beard et al., "Molecular and epidemiologic trends of caliciviruses associated with outbreaks of acute gastroenteritis in the United States, 2000-2004," Journal of Infectious Diseases, vol. 193, no. 3, pp. 413-421, 2006.

[29] C. Yen, M. E. Wikswo, B. A. Lopman, J. Vinje, U. D. Parashar, and A. J. Hall, "Impact of an emergent norovirus variant in 2009 on norovirus outbreak activity in the United States," Clinical Infectious Diseases, vol. 53, no. 6, pp. 568-571, 2011.

[30] The International Statistical Institute, 2014 List of Developing Countries, https://www.isi-web.org/index.php/resources/developing-countries.

[31] EU Bookshop, Organization of school time in Europe reports 1993/1994, 1994/1995, 1997/1998, 2000/2001, 2001/2002, 2002/2003, 2003/2004, 2004/2005, 2005/2006, 2006/2007, 20072008, 2008/2009, 20102011, 20112012, 2012/2013, http://bookshop.europa.eu/en/eacea-education-audiovisual-and-cultureexecutive-agency-cbLvYKABst3tgAAAEjFYcY4e5K/?Search Parameter $=\% 26 \% 40$ QueryTerm\%3D*\%26CorporateAuthors\% 3DLvYKABst3tgAAAEjFYcY4e5K\%26\%40Sort.LatestYear\% 3D1\%26\%40Page\%3D49\&SortingAttribute=PubYear_DESC\& PageSize $=10 . \% 20$ Accessed\%20November\%201,\%202014.

[32] New Zealand Ministry of Education, "School terms and holidays," http://www.minedu.govt.nz/theMinistry/EducationInNewZealand/SchoolTermsAndHolidays/SchoolTermsArchive.aspx.

[33] W. P. London and J. A. Yorke, "Recurrent outbreaks of measles, chickenpox and mumps. I. Seasonal variation in contact rates," American Journal of Epidemiology, vol. 98, no. 6, pp. 453-468, 1973.

[34] E. DiCaprio, Y. Ma, J. Hughes, and J. Li, "Epidemiology, prevention, and control of the number one foodborne illness. Human norovirus," Infectious Disease Clinics of North America, vol. 27, no. 3, pp. 651-674, 2013.

[35] Centres for Disease Control and Prevention, "Measles for healthcare professionals," 2015, https://www.cdc.gov/measles/hcp/. 


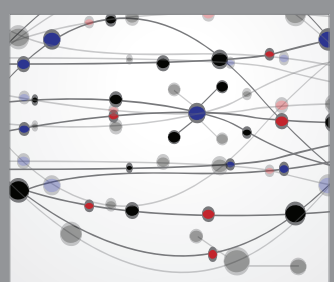

The Scientific World Journal
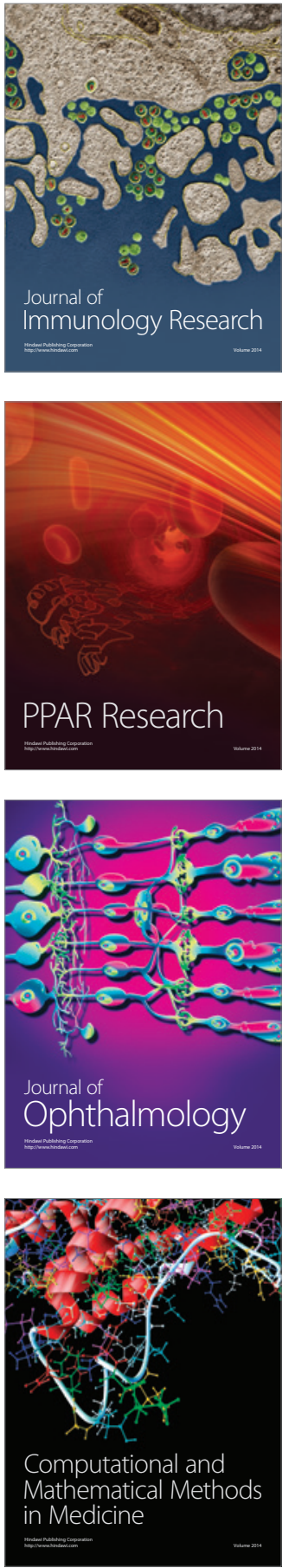

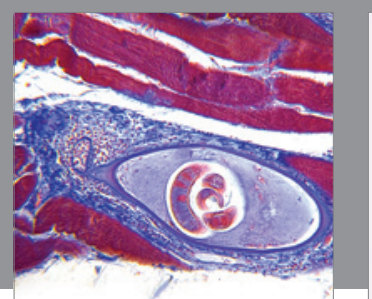

Gastroenterology Research and Practice
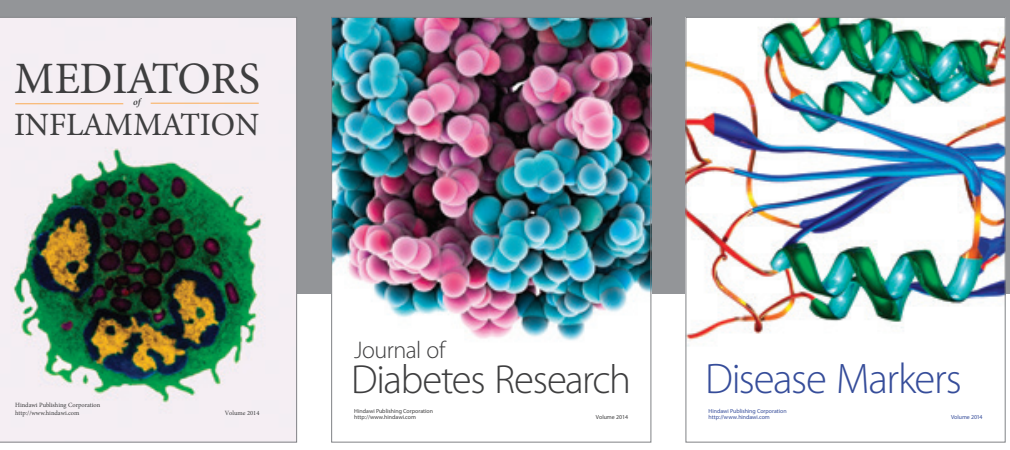

Disease Markers

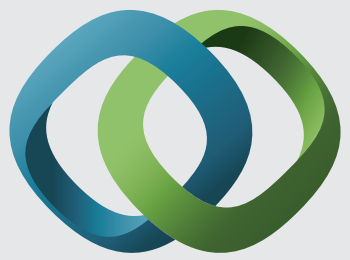

\section{Hindawi}

Submit your manuscripts at

https://www.hindawi.com
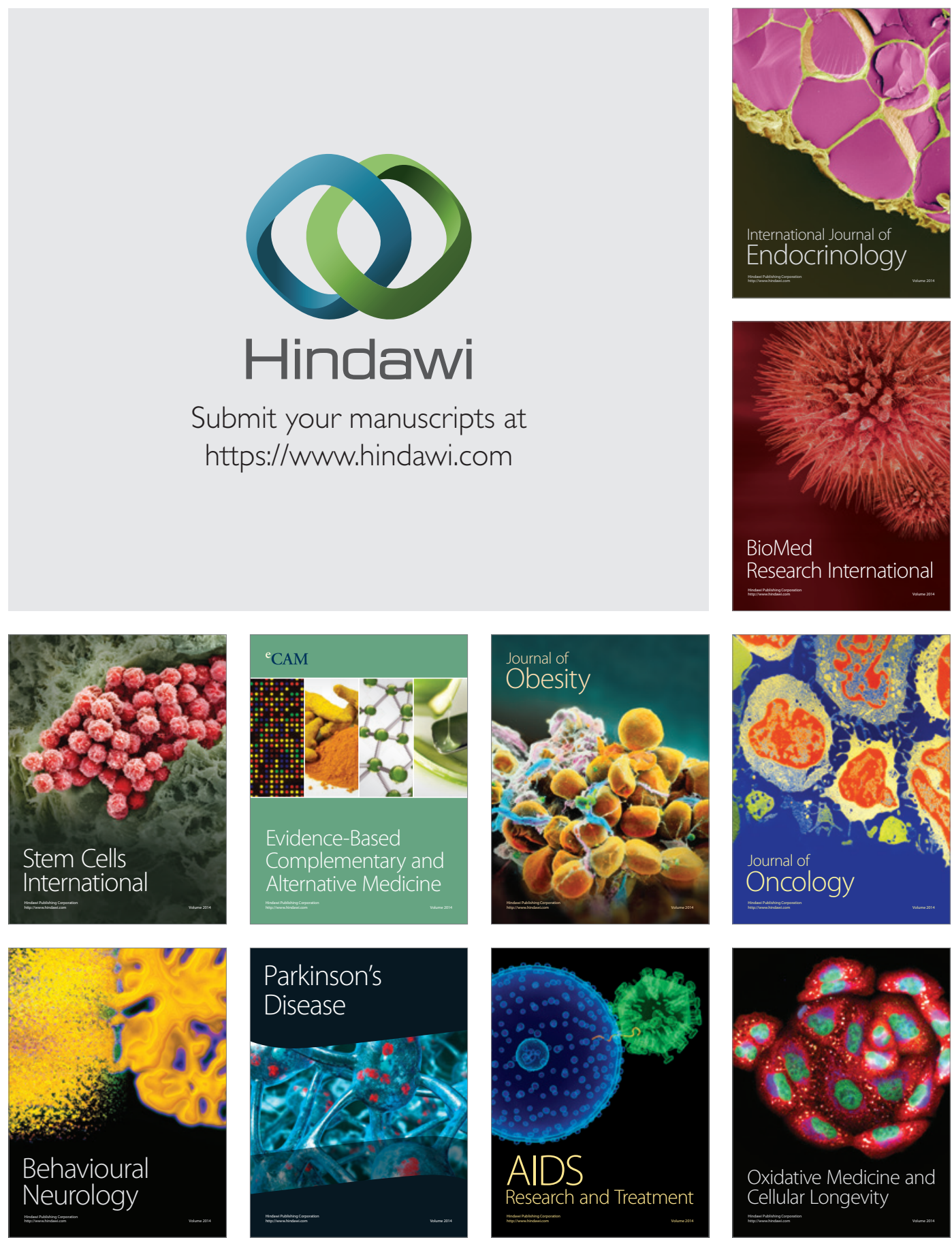